\title{
Affordable Care Act: 2016 Update
}

\author{
Gilbert Berdine MD
}

The memory of ACA's disastrous rollout with web site failures and other technical problems has faded from discussion. The technical problems, while demonstrating why important functions should never be trusted to government, were a distraction from the serious structural flaws in this program. ACA, like all government promises, offered something for nothing. ACA promised to insure more people at lower cost. It has been pointed out that it was impossible for ACA to achieve both goals simultaneously. ${ }^{1}$ While it is easy to increase the number of "insured" by offering subsidies, these subsidies must increase the price for health care. Let us examine what has happened to "insurance" premiums since ACA was introduced.

The words "insured" and "insurance" were placed in quotes because the modern notion of health "insurance" is so different from traditional insurance as to be unrecognizable as insurance. Let's examine traditional insurance, so that we can understand why ACA has had its effects on what are being called premiums. Traditional insurance is pooled risk against uncertain events that are beyond the control of the insured. That is why life insurance does not cover suicide and fire insurance does not cover arson. A storm at sea that sinks a merchant vessel is an insurable event. The insurance company charges a premium to the actuarial risk to cover expenses and provide a profit for funds that cannot be used for other purposes since they are required to be held in escrow against the possibility of covering claims. The insured accepts the insurance contract in order to pay a much smaller amount than putting aside the full cost of an insurable event. By pooling risk, the group of insured can cover risks out of current operations rather than

Corresponding author: Gilbert Berdine MD Contact Information: Gilbert.Berdine@ttuhsc.edu DOI: 10.12746/swrccc 2016.0413.169 setting aside a large amount of capital that would be unavailable for operating the business. For example, a household can pay a small sum for car insurance rather than setting aside the replacement cost of a vehicle in escrow to satisfy the lien holder of the car loan. Without an actuarially sound car insurance business, car loans would not be possible.

Stratification of risk serves an important purpose. Those with lower actuarial risks can be charged lower premiums making it more desirable for these people to participate in insurance. Those with high actuarial risks have a financial incentive to lower those risks where possible. This is why auto insurers charge lower premiums to drivers with good records and charge higher premiums to drivers who are prone to accidents. The elimination of risk stratification removes the incentive for low risk individuals to participate in insurance since they correctly perceive that they are paying a subsidy to other individuals with higher risks. While the desire not to penalize people for risks that are beyond control, such as genetic factors, elimination of risk stratification will not be voluntarily accepted by those with the lower risk.

One of ACA's features was the elimination of pre-existing conditions. It became illegal for insurance companies to charge a different premium for patients with certain costs than for patients who merely had a statistical likelihood of having costs. For example, if a patient has end stage renal disease, the cost of dialysis and other care is fairly straightforward to estimate. However, the insurance company could not charge that expected cost, but was required to charge the same premium irrespective of a client's renal function. By this seemingly well intended goal of insuring those with unfortunate circumstances, healthy people were forced to subsidize unhealthy people. The "premium" would be based on average expected costs for the entire population, so the healthy would pay a "premi- 
um" in excess of their actuarial risk and the unhealthy would receive a subsidy for their pre-existing condition. The only risk stratification permitted under ACA was for age and smoking status.

Under this homogenized risk scheme, the expected "premium" for "health insurance" becomes the cost of health care divided by the number of people. According to the Centers for Medicare \& Medicaid Services (CMS), the average annual cost of health care in the U.S. during 2014 was $\$ 9,523$ per person. ${ }^{2}$ CMS projects that this figure will increase by $4.8 \%$ per year through 2014. This is the lowest possible "premium" under ACA. Needless to say, this figure is a lot higher than what people are accustomed to paying under employer based group coverage. Some employers have responded to this sticker shock by dropping health insurance as a benefit. Some employers have responded by reclassifying many workers as part time. Some employers have offered the plans, but they have found that many of their employees cannot afford the plans without large subsidies. Even a stalwart supporter of ACA like the New York Times has reported on the difficulty for workers to get coverage under ACA. ${ }^{3}$ The Times notes that although some 14 million previously uninsured have obtained coverage under ACA, "Most of those gains, though, have come from a vast expansion of Medicaid and from the subsidies that help lower-income people buy insurance through federal and state exchanges." It is easy to give health care away; it is not so easy to get other people to voluntarily pay for benefits to strangers.

Actuaries are pretty good at predicting how many people in a group will get sick. They are not so good at predicting how many people will agree to pay subsidies by purchasing insurance that costs more than their perceived benefit. The "insurers" had to guess what mix of people would sign up. As a class, they guessed badly and the actual costs of coverage exceeded the initially offered premiums for policies. Consequently, despite initial sticker shock, the prices of plans are going up much faster than promised. Other companies, including the largest insurer - United Health - have decided to exit the ACA business due to huge losses on policies offered on Market Ex- changes. ${ }^{4}$

Advocates for ACA point to the accomplishment of reducing the number of uninsured. As stated earlier, it is easy to give something away; it is not so easy to pay for it. Some people are calling for the government to step in and offer something like Medicare for the entire population. These ideas ignore the problem that an entire nation cannot be subsidized; somebody has to pay for it. If the average person with an average income cannot afford health care, then no amount of redistribution will fix that problem. The only solution is to reduce health care expenditures, but the subsidies used to make ACA "affordable" must increase prices faster than otherwise would happen. The median household spends $14.5 \%$ of income on health insurance and out of pocket expenses. ${ }^{5}$ There is no correct figure, but if health costs are increasing and income is stagnant or declining, then health costs must crowd other items from the average household's budget.

Government subsidies must increase the cost of health care. Two changes in policy are necessary to reduce health care costs. The first change is to restore the traditional meaning of insurance to pooling risk. Catastrophic but rare events are insurable; certain events, such as an annual examination, are not. We must separate routine health maintenance from health insurance and restore competition to the provision of routine health maintenance. When each person directly bears the cost of his or her maintenance, providers will have to provide affordable health care or face bankruptcy. Price discovery is necessary to bring costs down. The next policy change that is necessary is to stop calling health care a right and treat health care like any other scarce economic resource. Every person is going to face end of life. Each person must decide during their golden years how much they should put aside for the difficulties of old age and infirmity. Tragic situations will be handled by charity, but the notion that each person has zero responsibility for his or her own care and $100 \%$ responsibility for everyone else's care is standing economic reality on its head. 
Author Affiliation: Dr. Gilbert Berdine is a pulmonary physician in the Department of Internal Medicine, TTUHSC.

Received: $1 / 2 / 2016$

Accepted: 1/11/2016

Published electronically: 1/15/2016

\section{References}

1.. http://www.pulmonarychronicles.com/ojs/index.php? journal $=$ pulmonarychronicles\&page $=$ article $\&$ op $=$ view\&path []$=62 \&$ path []$=134$

$2 . \quad$ https://www.cms.gov/Research-Statistics-Data-andSystems/Statistics-Trends-and-Reports/NationalHealthExpendData/NHE-Fact-Sheet.html

3. http://www.nytimes.com/2015/10/20/business/manylow-income-workers-say-no-to-health-insurance.html?smid=twshare \& $\mathrm{r}=1$

$4 . \quad$ http://www.bloomberg.com/news/articles/2015-12-01/ unitedhealth-says-it-should-have-stayed-out-of-obamacare-longer

5. http://www.urban.org/sites/default/files/alfresco/publication-pdfs/2000559-How-Much-Do-Marketplace-and-Other-

Nongroup-Enrollees-Spend-on-Health-Care-Relative-to-TheirIncomes.pdf 